\title{
Study of Serum Calcium and Serum Phosphorus Levels in Patients of Thalassemia Receiving Repeated Blood Transfusion
}

\author{
Anju R ${ }^{1}$, Shilpa Jain ${ }^{2}$ \\ Medical College Baroda, Vadodara
}

\begin{abstract}
A$ retrospective study with 40 patients of thalassemia, receiving repeated blood transfusion (Group A), and 40 age and sex matched controls (Group B) were included and serum calcium and phosphorus levels were checked.Data were analyzed.The serum calcium levels are statistically significantly lower in Group A compared to Group B, $(P<0.0001)$ but no significant alteration in serum phosphorus levels $(P=0.247)$. It might be due to iron overload in patients of group A,which alters the function of parathyroid gland and resulting in hypocalcemia. It may also be due to the binding of calcium by citrate content in Packed Red Cells.
\end{abstract}

Keywords: Thalassemia, Transfusion dependent, Citrate toxicity, Iron overload, Calcium status

\section{Introduction}

The term Thalassemia was coined by George Whipple in 1936. The name is derived from the Greek: Thalassa, meaning "sea" and Haima meaning "blood". Thalassemias, autosomal recessive disorders, are among the most prevalent genetic and major hemoglobin disorders globally. In Southern Asia, the prevalence of $\beta$ thalassemia has been reported to be from as low as $2 \%$ to as high as $28 \%$ in various studies[1-3].

It is characterized by the complete absence or reduced synthesis of one or more types of globin chains. The affected infants present with pallor, poor growth, and abdominal enlargement due to hepatosplenomegaly. In untreated children, characteristic bone changes appear, such as thinning of cortex of long bones, widening of medullary spaces, bossing of the skull, widening of display spaces, and prominence of the upper incisors and separation of orbit[4].

The mainstay of treatment of severe $\beta$ thalassemia is regular blood transfusion with an attempt to maintain hemoglobin levels greater than $10 \mathrm{~g} / \mathrm{dl}$. Repeated blood transfusions results in citrate toxicity and also leads to iron deposition in the parathyroid gland, which in turn may cause hypoparathyroidism. A few studies have reported that some of the thalassemic patients on regular PCV infusion develop hypoparathyroidism, especially after 10 years of age . Limited studies have also shown that supplementation with vitamin D and calcium improves serum calcium status[4].

$\beta$-thalassemia major patients present within the first year of their life and require regular, lifelong blood transfusions for correction of anemia. These frequent transfusions lead to iron overload which itself is fatal by the second decade of life. With the advent of chelation therapy, the survival of thalassemia major patients has increased and they are entering even into third and fourth decades of life. Inspite of chelation therapy, iron overload related complications like endocrinopathies are still occuring. Thus, there might be other mechanisms too responsible for these problems. Common endocrine disorders reported in $\beta \quad$-thalassemia major patients are short stature,hypogonadism, hypoparathyroidism, hypothyroidism and diabetes mellitus. Many studies have been done on endocrine disorders including hypoparathyroidism in thalassemia patients and frequency reported varies from centre to centre but largest study so far done included 1861 patients from 25 centres and showed that $3.6 \% \beta \quad$-thalassemia major patients had hypoparathyroidism[1]. Lack of such studies in the Indian set up prompted me to conduct a study on thalassemia patients with repeated blood transfusion.

\section{Objectives}

- To determine the levels of serum calcium and serum phosphorus in patients of thalassemia receiving repeated blood transfusion.

- To compare the levels of serum calcium and phosphorus in thalassemia patients with age and sex matched controls.

\section{Materials and Methods}

Retrospective cross sectional study comprised of 80 subjects taken from the Pediatric department of S S G Hospital and Medical College, Baroda, Vadodara.

- Group A- 40 patients of thalassemia, who have received repeated blood transfusion.

- Group B- 40 age and sex matched controls.

In both the groups serum calcium and serum phosphorus levels are checked using Arsenazo III \& UV Molybdate method respectively on a fully automated biochemistry analyzer cobas c-311. Blood samples were collected before giving transfusion.

\section{Inclusion Criteria}

- Age 4-18 years.

- Diagnosis of thalassemia major.

- Those recieved regular PRC infusion and chelation therapy.

- For controls, between age 4- 18 years without thalassemia. 
International Journal of Science and Research (IJSR)

ISSN (Online): 2319-7064

Index Copernicus Value (2015): 78.96 | Impact Factor (2015): 6.391

Exclusion Criteria

- Poor compliance.

- Very sick.

- Patients on long term anticonvulsant therapy.

\section{Observations}

Table 1 shows the demographic profile of the subjects in the study.

Table 1: Demographic Profile

\begin{tabular}{|c|c|c|c|}
\hline & Group A & Group B & P value \\
\hline Total No. of cases & 40 & 40 & - \\
\hline $\begin{array}{c}\text { Age(Mean } \pm \text { SD) } \\
\text { (years) }\end{array}$ & $6.35 \pm 2.27$ & $7.05 \pm 2.94$ & $\mathrm{P}=0.23$ \\
\hline Males(\%) & $21 / 40(52.5 \%)$ & $20 / 40(50 \%)$ & $\mathrm{P}=1.0$ \\
\hline Females(\%) & $19 / 40(47.5 \%)$ & $20 / 40(50 \%)$ & $\mathrm{P}=1.0$ \\
\hline
\end{tabular}

In present study, the two groups were age and sex matched. The mean(SD) age of Group A was 6.35( \pm 2.27$)$ and of Group B was 7.05 $( \pm 2.94)$. $52.5 \%$ were males in Group A and $50 \%$ in GroupB, females were $47.5 \%$ and $50 \%$ in group $\mathrm{A}$ and $\mathrm{B}$ respectively.

Table 2 and Figure 1 show the levels of serum calcium in two groups.

Table 2: Serum calcium levels in two groups

\begin{tabular}{|c|c|c|c|}
\hline Parameter & Group A & Group B & P value \\
\hline $\begin{array}{c}\text { Serum Calcium in mg } \\
\%(\text { mean } \pm \text { SD })\end{array}$ & $6.9 \pm 0.50$ & $9.4 \pm 0.40$ & $\mathrm{P}<0.0001$ \\
\hline Range & $5.9-7.9$ & $8.6-10.2$ & \\
\hline
\end{tabular}

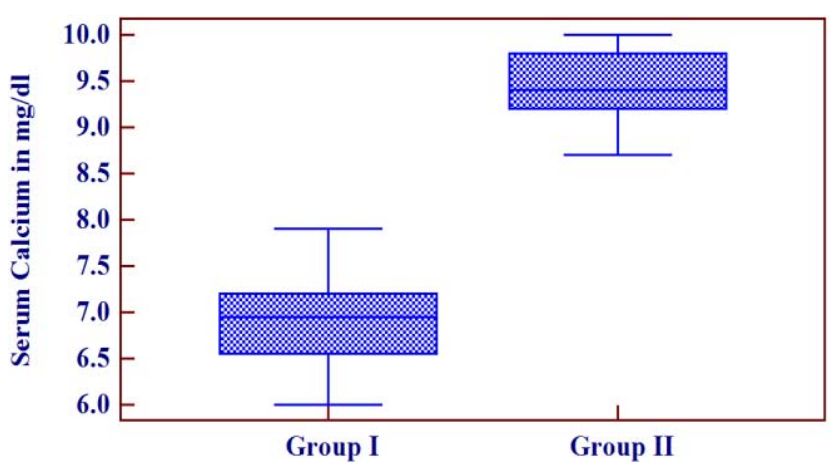

Figure 1: Serum calcium levels in two groups

Table 2 and figure 1 show a statistically significant difference in the serum calcium levels between two groups( $\mathrm{P}$ value $<0.0001)$. The mean(SD) levels of serum calcium in group A is $6.9( \pm 0.5)$ and in group B is $9.4( \pm 0.4) .82 \%$ of patients with thalassemia in group A showed hypocalcemia.

Table 3 and Figure 2 show the levels of serum phosphorus in two groups.

Table 3: Serum Phosphorus levels in two groups

\begin{tabular}{|c|c|c|c|}
\hline $\begin{array}{c}\text { Parameter } \\
\begin{array}{c}\text { Serum Phosphorus in } \\
\text { mg \% (mean } \pm \text { SD) }\end{array}\end{array}$ & $3.9 \pm 0.19$ & $4.0 \pm 0.16$ & $\mathrm{P}=0.247$ \\
\hline Range & $3.5-4.2$ & $3.71-4.29$ & \\
\hline
\end{tabular}

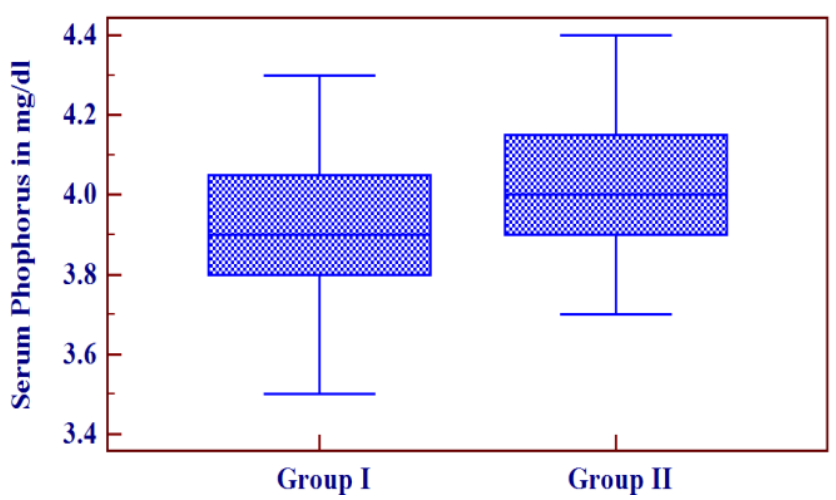

Figure 2: Serum Phosphorus levels in two groups

Table 3 and figure 2 do not show any statistically significant difference in the serum phosphorus levels between two groups( $\mathrm{P}$ value $=0.247)$. The mean $(\mathrm{SD})$ levels of serum phosphorus in group A is $3.9( \pm 0.19)$ and in group B is 4.0 $( \pm 0.16)$

\section{Discussion}

A retrospective cross sectional study was conducted with 40 patients of beta thalassemia major who had received repeated blood transfusion in Group A and 40 controls in Group B. In the study, the two groups were age and sex matched. The mean (SD) age of the study in group A is $6.35(2.27)$ and in group $\mathrm{B}$ is 7.05(2.94). The mean $\pm \mathrm{SD}$ of serum calcium levels in group A $(6.9 \pm 0.5)$ is significantly lower than in group B $(9.4 \pm 0.4) \quad \mathrm{P}<0.0001 .82 \%$ of patients with thalassemia in group A showed hypocalcemia. But there is no statistically significant difference in the levels of phosphorus $(\mathrm{P}=0.247)$.

Study by Shah on thalassemia major patients with chelation therapy showed that low serum calcium is very prevalent in transfusion-dependant beta thalassemia major patients possibly due to poor chelation and confirmed by her study where $49 \%$ of patients had hypocalcemia. Mean serum calcium levels of participants of this study was $8.46 \pm 0.94$ $\mathrm{mg} / \mathrm{dl}(6-11 \mathrm{mg} / \mathrm{dl})$. The mean phosphorus level was $5.33 \pm 0.77 \mathrm{mg} / \mathrm{dl}(4-6.9 \mathrm{mg} / \mathrm{dl}) .26$ out of 100 patients had hypocalcemia associated with hyperphosphatemia[1].

Another study by Anuj S Modi et al found out that $84 \%$ patients with thalassemia major, in spite of chelation therapy, have hypocalcemia and the serum phosphate levels in these patients were normal but in higher range than the controls and the difference was statistically significant[5].

Hypocalcemia is reported to be $16.6 \%$ by Dresner et al[6] while Gulati et al. reported it to be $13.5 \%$ and hyperphosphatemia was found in $60 \%$ of those who had hypocalcemia[7]. Hypocalcemia and hyperphosphatemia was detected in $22 \%$ and $18 \%$ respectively by Mirrhosseini et al[8] in patients of thalassemia receiving repeated blood transfusion.

Hypocalcemia occurring in $\beta$-thalassemia major is attributed to hypopoparathyroidism mainly. Low parathyroid hormone levels lead to excessive calcium loss in urine, decreased bone remodeling and decreased intestinal absorption of calcium. Hypocalcemia can also occur with massive blood 


\section{International Journal of Science and Research (IJSR) \\ ISSN (Online): 2319-7064 \\ Index Copernicus Value (2015): 78.96 | Impact Factor (2015): 6.391}

transfusions due to the complex of citrate with serum calcium. RBCs in additive solution contain only traces of citrate, however, FFP and platelets contain much higher concentrations. Citrate binds calcium, thus lowering the ionized plasma calcium concentration[9].

While literature search I found a handfull of studies, whose results are matching with my study.

The current study was designed for assessment of serum calcium and phosphorus among transfusion-dependent $\beta$ thalassemia major patients in our set up where delay in starting chelation therapy and non-compliance is common. This study will be useful in setting recommendations regarding Calcium and Vitamin D supplementation and periodic assessment of calcium levels among transfusiondependant $\beta$ thalassemia major.

The limitations of the study are no correlation with serum ferritin levels have not been done to detect the iron overload and serum levels of Parathyroid hormone also not done to find out hypoparathyroidism.

\section{Conclusion}

- The serum calcium levels in patients of $\beta$ thalassemia major who have received repeated blood transfusion is statistically significantly lower compared to age and sex matched controls.

- There was no statistically significant difference between the levels of phosphorus in two groups.

- It might be due to iron overload in patients receiving repeated blood transfusion which alters the function of the parathyroid gland and finally results in hypocalcemia or may be due to the citrate content in Packed Red Cells used for transfusion which can bind the calcium in the blood.

So it is important to check the serum calcium levels in patients with thalassemia receiving repeated blood transfusion.

\section{References}

[1] Shah S. Assessment of serum calcium and phosphorus levels among transfusion-dependent ßeta thalassemia major patients on chelation therapy. J Postgrad Med Inst 2015; 29(3): 168-71

[2] Mohanty D, Colah RB, Gorakshakar AC, Patel RZ, Master DC, Mahanta J, et al. Prevalence of $\beta$-thalassemia and other haemoglobinopathies in six cities in India: a multicentre study. J Community Genet. 2013; 4:33-42

[3] Uddin MM, Akteruzzaman S, Rahman T, Hasan AK, Shekhar HU. Pattern of $\beta$-Thalassemia and Other Haemoglobinopathies: A Cross-Sectional Study in Bangladesh. ISRN Hematol. 2012;2012:659191

[4] Goyal M, Abrol P, Lal H. Indian Journal of Clinical Biochemistry. October 2010; 25(4):385-7.

[5] Modi AS, Poornima RT, Murthy J.D.S. Serum calcium and phosphate levels in patients with $\beta$ - thalassemia major. IJPBS.2012;2(4):156-160.

[6] Dresner PR, Rachmilewitz E, Blumenfeld A, Idelson M, Goldfarb AW. Bone mineral metabolism in adults with beta-thalassaemia major and intermedia. $\mathrm{Br} \mathrm{J}$ Haematol 2000; 111(3): 902-7.
[7] Gulati R, Bhatia V, Agarwal SS. Early onset of endocrine abnormalities in $\beta$ thalassemia major in a developing country. J Pediatr Endocrinol Metab. 2000; 13(6):651-6.

[8] Mirhosseini NZ, Shahar S, Ghayour-Mobarhan M, Banihashem A, Kamaruddin NA, Hatef MR . Bone-related complications of transfusion-dependent $\beta$ thalassemia among children and adolescents. $J$ Bone Miner Metab.2013;31(4):468-76.

[9] Donaldson MDJ, Seaman MJ, Park GR. Massive blood transfusion. Br J Anaesth. 1992; 69:621-30.

\section{Author Profile}

$3^{\text {rd }}$ year resident, MD Biochemistry, Medical College, Baroda, Vadodara 